\title{
Platelet polyphosphate level is elevated in patients with chronic primary thrombocytopenia: A preliminary study
}

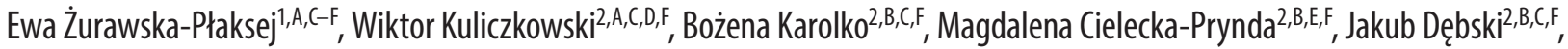 \\ Konrad Kaaz ${ }^{2, B, E, F}$, Andrzej Mysiak ${ }^{2, A, E, F}$, Tomasz Wróbe ${ }^{3, B, E, F}$, Maria Podolak-Dawidziak ${ }^{3,-}$, , Lidia Usnarska-Zubkiewicz ${ }^{1, A, E, F}$ \\ ${ }^{1}$ Department of Pharmaceutical Biochemistry, Wroclaw Medical University, Poland \\ 2 Department and Clinic of Cardiology, Wroclaw Medical University, Poland \\ ${ }^{3}$ Department of Hematology, Blood Neoplasms and Bone Marrow Transplantation, Wroclaw Medical University, Poland \\ A - research concept and design; $B$ - collection and/or assembly of data; $C$ - data analysis and interpretation; \\ $D$ - writing the article; $E$ - critical revision of the article; $F$ - final approval of the article
}

Address for correspondence

Ewa Żurawska-Płaksej

E-mail: ewa.zurawska-plaksej@umed.wroc.pl

Funding sources

Internal grant of Wroclaw Medical University,

Poland, No. ST C. 14.16.077

Conflict of interest

None declared

Received on February 16, 2020

Reviewed on May 4, 2020

Accepted on July 16, 2020

Published online on September 18, 2020

Cite as

Żurawska-Płaksej E, Kuliczkowski W, Karolko B, et al. Platelet polyphosphate level is elevated in patients with chronic primary thrombocytopenia: A preliminary study. Adv Clin Exp Med. 2020;29(9):1051-1056.

doi:10.17219/acem/125430

DOI

10.17219/acem/125430

Copyright

Copyright by Author(s)

This is an article distributed under the terms of the

Creative Commons Attribution 3.0 Unported (CC BY 3.0)

(https://creativecommons.org/licenses/by/3.0/)

\begin{abstract}
Background. Platelets are key players in hemostasis. These blood cells contain different types of granules. Recently, there has been a growing interest in the role of inorganic polyphosphate (polyP) structures stored in dense granules of platelets and secreted during platelet activation.

Objectives. To measure platelet polyP levels in patients with thrombocytopenia and thrombocythemia, and to examine the relationship of this indicator with platelet aggregation.

Material and methods. The study included 36 patients with hematological disorders (26 with primary chronic thrombocytopenia and 10 with essential thrombocythemia (ET)) and 40 healthy subjects. Platelet reactivity was measured using whole blood impedance aggregometry. The polyP levels were isolated from lysed platelets, which were obtained from citrated platelet-rich plasma. The procedure included inactivating endogenous phosphatases, removing phosphate units derived from DNA and proteins, and finally hydrolyzing them into monophosphate units. A colorimetric assay using malachite green and ammonium molybdate was performed in order to quantify polyP levels.
\end{abstract}

Results. The polyP concentrations were significantly higher in the patients with thrombocytopenia than in the patients with thrombocythemia or the controls. The polyP level was not correlated with the level of aggregation.

Conclusions. The higher polyP levels observed in the patients with low platelet counts may indicate the existence of a compensatory mechanism that prevents excessive bleeding in such patients. Our study provides evidence of an essential role of polyP in platelet function and the coagulation process.

Key words: coagulation, platelets, thrombocytopenia, essential thrombocythemia, platelet polyphosphate 


\section{Introduction}

Platelets are small, highly specialized anucleate blood cells that participate in primary hemostasis, forming a platelet plug at sites of vascular injury to prevent blood loss. Platelets become activated in response to various stimuli, triggering the release of their granular contents into the surrounding environment. Platelets contain $\alpha$-granules, dense granules and lysosomes. Platelet dense granules contain a unique pool of molecules (e.g., serotonin [5-HT], nucleotides and polyphosphate (polyP) that can also provide a sensitive measurement of platelet activity. Platelet polyP is a highly anionic, linear strand of inorganic orthophosphate residues connected by high-energy phosphoanhydride bonds; it is found in all living organisms. ${ }^{1}$ Platelet-derived polyP composed of about 60-100 phosphate monomers in length accelerates factor $\mathrm{V}$ activation, opposes the anticoagulant action of tissue factor pathway inhibitor (TFPI), modulates fibrin clot structure and promotes factor XI activation. ${ }^{2}$ Due to its highly anionic nature, polyP lends itself to being a natural activator of the contact system. Activation of the contact system accelerates thrombin generation. The net effect is increased fibrin formation and platelet activation, resulting in faster clot formation. The polyP is incorporated into the forming clot, thereby modifying the structure of the resulting fibrin network and its susceptibility to degradation by certain plasminogen activators. ${ }^{3}$ Studies in mice and human plasma also revealed that polyP can serve as the long soughtafter FXII-activating surface on activated platelets to link primary and secondary hemostasis. ${ }^{4}$ Patients with polyP deficiency (Hermansky-Pudlak syndrome) have defective platelet-driven FXII activation and clotting. ${ }^{5}$ On the other hand, the circulating von Willebrand factor (VWF) isolated from human platelets and plasma was shown to contain tightly bound polyP, which can enhance VWF ristocetin cofactor activity without affecting the bonding of VWF to collagen or VWF multimerization. ${ }^{6}$

Apart from many animal and in vitro studies, the data on polyP in humans is still not wholly understood. Starting from the basics, there are no data on the relationship between platelet polyP level and platelet count or between platelet polyP level and its reactivity.

The aim of this study was to measure platelet polyP levels in patients with thrombocytopenia and thrombocytosis, and to correlate it to platelet aggregation.

\section{Material and methods}

\section{Patients}

Patient recruitment was carried out as part of the project entitled "Assessment of the Efficacy and Safety of Antiplatelet Therapy in Patients with Multiple Myeloma and Essential Thrombocythemia Cancer
Undergoing Invasive Diagnostic and Therapeutic Procedures" (internal grant of Wroclaw Medical University, Poland, No. STC.140.16.077). The study involved 36 patients with hematological disorders: 26 with primary chronic thrombocytopenia and 10 with essential thrombocythemia (ET) attending the outpatient clinic at the Department of Hematology, Blood Neoplasms and Bone Marrow Transplantation in Wrocław, Poland. Forty healthy adults with no history of thrombosis or bleeding events served as controls. Neither the patients nor the controls were treated with antiplatelet drugs. The patients with thrombocythemia had been treated with hydroxycarbamide or aspirin in the past, but they were not actively being treated during the study. The study was approved by the Bioethics Committee of Wrocław Medical University in accordance with the Declaration of Helsinki of 1975, as revised in 2000. All patients and controls provided written informed consent for the study. The characteristics of the patients and controls are presented in Table 1.

The normal platelet count in adults ranges between $150.0 \times 10^{9} / \mathrm{L}$ and $450.0 \times 10^{9} / \mathrm{L}$. Thrombocytopenia was defined as a platelet count of less than $150 \times 10^{9} / \mathrm{L}$, while thrombocytosis was defined as a platelet count of more than $450 \times 10^{9} / \mathrm{L}$. Blood for polyP level and platelet aggregation was drawn the morning after at least $6 \mathrm{~h}$ of overnight fasting from the antecubital vein with a $21 \mathrm{G}$ needle.

\section{Platelet aggregation}

Platelet reactivity was measured with whole blood impedance aggregometry (Multiplate analyzer; Roche Diagnostics, Basel, Switzerland). According to the manufacturer's instruction, impedance aggregometry does not require platelet count adjustments in the test probe before starting aggregation. Aggregation agonists included arachidonic acid (AA) at a target concentration of $0.5 \mathrm{mM}$, adenosine diphosphate (ADP) at a target concentration of $6.4 \mu \mathrm{M}$ and thrombin receptor agonist peptide (TRAP) at a target concentration of $32 \mu \mathrm{M}$. The reagents were provided by the manufacturer of the aggregometer. Aggregation was assessed within $2 \mathrm{~h}$ of blood sampling with hirudin as an anticoagulant; the results were described by the area under the aggregation curve (AUC). Each aggregation measurement was performed twice, and the mean value was calculated. In the case of a $10 \%$ difference between the 2 measurements, the result was rejected and aggregation was repeated.

\section{Platelet polyP}

A non-enzymatic assay to quantify platelet-derived polyP in cell lysates from patients was developed from various methods described for measuring polyP in biological samples. ${ }^{7-9}$ After collecting blood into sodium citrate tubes (Vacutainer; Becton Dickinson, Franklin Lakes, USA), 9:1 (blood-to-citrate ratio) prostaglandin $\mathrm{I}_{2}\left(\mathrm{PGI}_{2}\right.$; 
Table 1. Patient characteristics, results of platelet aggregometry measurements and level of platelet-derived polyphosphate in the study groups

\begin{tabular}{|c|c|c|c|c|}
\hline \multirow[t]{2}{*}{ Variable } & $\begin{array}{l}\text { Thrombocytopenia } \\
\qquad(n=26)\end{array}$ & $\begin{array}{l}\text { Essential } \\
\text { thrombocythemia } \\
(n=10)\end{array}$ & $\begin{array}{l}\text { Controls } \\
(n=40)\end{array}$ & \multirow[t]{2}{*}{$\begin{array}{l}\text { Statistical significance } \\
\text { from post hoc tests }\end{array}$} \\
\hline & $(1)$ & (2) & (3) & \\
\hline Age [years], mean $\pm S D$ & $68 \pm 10$ & $56 \pm 22$ & $61 \pm 9$ & $\begin{array}{l}\text { (1) vs (2) } p<0.0001 \\
\text { (1) vs (3) } p<0.0001\end{array}$ \\
\hline Gender (men/women) & $14 / 12$ & $5 / 5$ & $19 / 21$ & NS \\
\hline $\mathrm{PLT}\left[\times 10^{9} / \mathrm{L}\right]$, mean $\pm \mathrm{SD}$ & $73 \pm 34$ & $686 \pm 230$ & $176 \pm 75$ & (1) vs (2) vs (3) $p<0.001$ \\
\hline $\mathrm{MPV}[\mathrm{fL}]$, mean $\pm \mathrm{SD}$ & $9.7 \pm 1.3$ & $9.1 \pm 0.89$ & $9.4 \pm 1.1$ & NS \\
\hline $\mathrm{Hb}[\mathrm{g} / \mathrm{dL}]$, median $(\mathrm{IQR})$ & $10.4(9.1-12.6)$ & $13.3(12.3-13.4)$ & $13.0(11.5-14.1)$ & $\begin{array}{l}\text { (1) vs (2) } p<0.0001 \\
\text { (1) vs (3) } p<0.0001\end{array}$ \\
\hline Ht [\%], median (IQR) & $34.0(28.5-39.2)$ & $41.2(38.2-44.6)$ & $40.8(36.4-42.5)$ & $\begin{array}{l}\text { (1) vs (2) } p<0.0001 \\
\text { (1) vs (3) } p<0.0001\end{array}$ \\
\hline $\mathrm{RBC}\left[\times 10^{12} / \mathrm{L}\right]$, mean $\pm \mathrm{SD}$ & $3.6 \pm 0.8$ & $4.5 \pm 0.7$ & $4.1 \pm 0.7$ & $\begin{array}{l}\text { (1) vs (2) } p<0.0001 \\
\text { (1) vs (3) } p<0.0001\end{array}$ \\
\hline WBC $\left[\times 10^{9} / L\right]$, median (IQR) & $5.3(3.2-7.1)$ & $9.0(7.3-9.7)$ & $6.4(5.3-7.9)$ & $\begin{array}{l}\text { (2) vs (1) } p<0.0001 \\
\text { (2) vs (3) } p<0.0001\end{array}$ \\
\hline AA-induced aggregation $[\mathrm{AUC}]$, mean $\pm \mathrm{SD}$ & $33.7 \pm 28.5$ & $74.7 \pm 46.6$ & $34.8 \pm 30.9$ & $\begin{array}{l}\text { (2) vs }(1) p<0.001 \\
\text { (2) vs (3) } p<0.001\end{array}$ \\
\hline ADP-induced aggregation (AUC], mean $\pm S D$ & $43.1 \pm 27.7$ & $107.2 \pm 40.8$ & $51.4 \pm 26.3$ & $\begin{array}{l}\text { (2) vs }(1) p<0.001 \\
\text { (2) vs (3) } p<0.001\end{array}$ \\
\hline TRAP-induced aggregation $[A \cup C]$, mean $\pm S D$ & $60.9 \pm 28.9$ & $117.7 \pm 17.4$ & $86.8 \pm 28.2$ & $\begin{array}{l}\text { (2) vs }(1) p<0.001 \\
\text { (2) vs (3) } p<0.001\end{array}$ \\
\hline PolyP [nmol per $10^{8}$ platelets], median (IQR) & $1.62(1.24)$ & $1.29(0.22)$ & $1.12(0.92)$ & $\begin{array}{l}\text { (1) vs (3) } p=0.007 \\
\text { (1) vs (2) } p=0.006\end{array}$ \\
\hline Arterial hypertension & 12 & 5 & - & NS \\
\hline Diabetes & 1 & 1 & - & NS \\
\hline Ischemic heart diseases & 0 & 1 & - & NS \\
\hline Kidney insufficiency & 1 & 1 & - & NS \\
\hline Gout & 0 & 1 & - & NS \\
\hline
\end{tabular}

PLT - platelets; MPV - mean platelet volume; Hb - hemoglobin; Ht - hematocrit; RBC - red blood cells; WBC - white blood cells; AA - arachidonic acid; ADP - adenosine 5-diphosphate; TRAP - thrombin receptor agonist peptide-6; AUC - area under curve; SD - standard deviation; IQR - interquartile range.

Cayman Chemicals, Ann Arbor, USA) was carefully added to a final concentration of $5 \mu \mathrm{M}$ in order to prevent platelet activation. A platelet fraction was obtained through the standard procedure. In brief, blood was centrifuged at $200 \times \mathrm{g}$ for $20 \mathrm{~min}$ at room temperature without braking. The resulting platelet-rich plasma (PRP) was transferred into a new plastic tube, supplemented with $\mathrm{PGI}_{2}$ (final concentration of $1 \mu \mathrm{M}$ ) and centrifuged at $900 \times \mathrm{g}$ for $10 \mathrm{~min}$ (room temperature, no braking). The platelet pellet was washed in HEPES buffer (20 mM HEPES, $140 \mathrm{mM} \mathrm{NaCl}$ and $\left.1 \mu \mathrm{M} \mathrm{PGI}_{2}\right)$ by centrifugation for $10 \mathrm{~min}(800 \times \mathrm{g}$, room temperature, no braking). To measure the total plateletderived polyP, the cells were lysed with $1 \mathrm{~mL}$ of HEPES buffer supplemented with 1\% NP40 (Sigma-Aldrich, St. Louis, USA), a 1:100 protease inhibitor cocktail (Thermo Fisher, Waltham, USA), and $1 \mathrm{mM}$ sodium orthovanadate; they were then counted in a complete blood count (CBC) hematological analyzer (Shenzen Mindry Bio-Medical Electronic Co., Shenzen, China) and frozen at $-80^{\circ} \mathrm{C}$. Before measurement, the samples were subjected to a triple freeze-thaw cycle and diluted to $3 \times 10^{8}$ cells $/ \mathrm{mL}$. The total protein concentration was measured with a Pierce ${ }^{\mathrm{TM}} \mathrm{BCA}$ Protein Assay Kit (Thermo Fisher). Next, sulfuric acid $(0.3 \mathrm{M})$ and sodium chloride $(3.5 \mathrm{M})$ was added to the lysates in order to extract membrane-bound polyP. The mixtures were incubated for $30 \mathrm{~min}$ at $4^{\circ} \mathrm{C}$, neutralized with $2 \mathrm{M} \mathrm{NaOH}$, sonicated (60 s) and homogenized. To remove nucleic acids, the lysates were incubated with $50 \mu \mathrm{g} / \mathrm{mL}$ Benzonase $^{\circledR}$ (Sigma-Aldrich) in the presence of $3.5 \mathrm{mM}$ manganese (II) chloride as an activator for $30 \mathrm{~min}$ at $37^{\circ} \mathrm{C}$. Then, $750 \mu \mathrm{g} / \mathrm{mL}$ of proteinase K (Sigma-Aldrich) was added to discard protein impurities $\left(1 \mathrm{~h}\right.$ incubation at $\left.37^{\circ} \mathrm{C}\right)$. Subsequently, the samples were centrifuged for $10 \mathrm{~min}$ at $17,600 \times \mathrm{g}$ in a microcentrifuge and the supernatants were used in the next stages of the isolation procedure. After the addition of $\mathrm{NaI}$ (final concentration of $4.5 \mathrm{M}$ ) as a chaotropic agent, the mixtures were loaded onto silica spin columns (Qiagen, Hilden, Germany), washed twice with an elution buffer (with 50\% ethanol) according to the manufacturer's protocol and the polyP was finally eluted with $10 \mathrm{mM}$ Tris (pH 7.4). The phosphate polymers were hydrolyzed with $1 \mathrm{M} \mathrm{HCl}\left(1 \mathrm{~h}\right.$ of incubation at $\left.96^{\circ} \mathrm{C}\right)$. 
The concentration of orthophosphate units was measured using a colorimetric phosphate assay kit (Abcam, Cambridge, UK). The assay involves a formulation of malachite green and ammonium molybdate which forms a chromogenic complex at a maximum absorption band of $650 \mathrm{~nm}$. The polyP levels were expressed in nmol per $10^{8}$ platelets.

\section{Statistical analysis}

The statistical analysis was performed in STATISTICA v. 13.1 (StatSoft Poland, Kraków, Poland). The data is presented as means \pm standard deviation (SD) for normal distributions and as medians with interquartile ranges (IQR) in non-normal distributions. The normality of distribution and homogeneity of variance were checked with the Lilliefors test and Levene's test, respectively. In normally distributed data, multiple comparisons were performed with the analysis of variance (ANOVA) method followed by the least significant differences (LSD) post hoc test; in data without normal distribution, the Kruskal-Wallis test was followed by the Dunn test. Bonferroni adjustment was used for multiple comparisons with a resulting $\mathrm{p}<0.01$ as the cut-off threshold for statistical significance.

\section{Results}

In patients with ET, the platelet aggregation level was significantly higher than in those with thrombocytopenia or the controls (Table 1). We observed the highest mean polyP concentration in patients with thrombocytopenia (Fig. 1). The level of polyP did not correlate with platelet aggregation in either group. There was a weak, but significant negative correlation between polyP concentration and platelet count (Fig. 2). However, this was observed only in the total population, not in subgroups. Patients with thrombocytopenia differed significantly in age from the ET and control groups, but neither the level of aggregation or the concentration of polyP correlated with age.

\section{Discussion}

Platelet-derived polyP has been proposed as an important player in the coagulation network at the level of FXII FV and fibrin clot formation. ${ }^{10,11}$ Recent findings have yielded new insights into the undiscovered regulatory pathways of coagulation reactions and have created new therapeutic possibilities. In this study, we showed for the first time that platelet-derived polyP levels are significantly elevated in patients with a low platelet count in comparison to those with normal platelet counts or thrombocytosis. These patients also had the lowest levels of aggregation, but this result was not significantly different from the control subjects. We could not find any

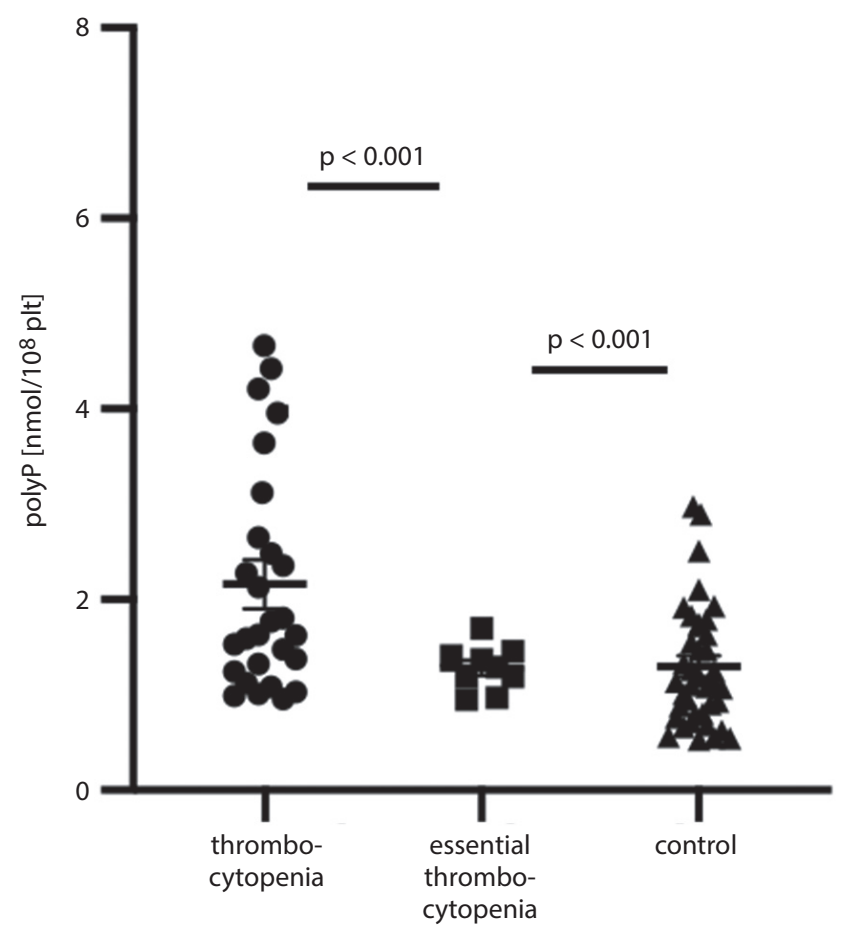

Fig. 1. Platelet-derived polyP level in patients with different platelet count

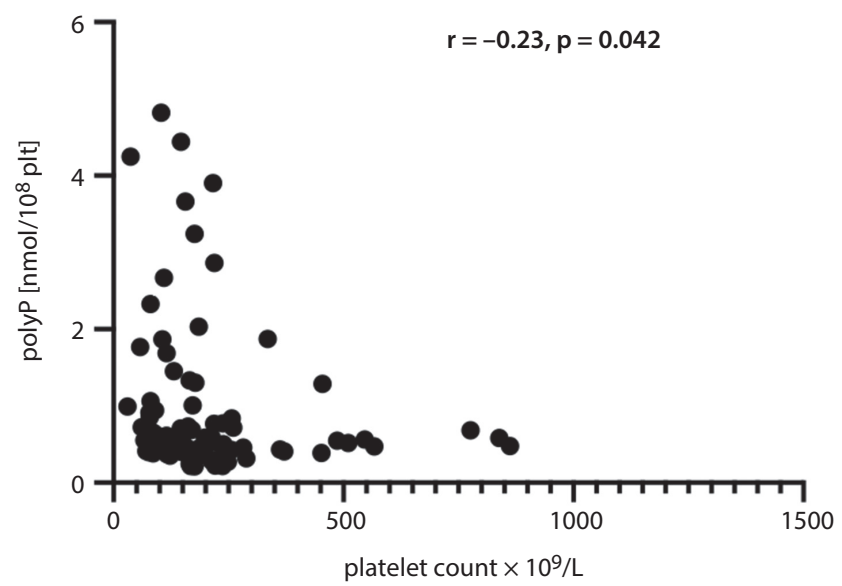

Fig. 2. Correlation plot of polyP concentration and platelet count

correlation between polyP concentration and aggregation level in the study groups, which may at first glance suggest that polyP does not directly influence the platelet aggregation pathway. This is in accordance with evidence provided by Whyte et al. ${ }^{12}$ that polyP downregulates fibrinolysis by generating fibrin clots with a specific structure, which results in reduced binding of tPA and plasminogen to fibrin, as proposed previously. ${ }^{13}$ The authors showed that the fibrin network formed in the presence of polyP was heterogeneous and more resistant to degradation by fibrinolytic proteases. Any changes to the structure or mechanical properties of a fibrin clot are not detectable using aggregometry. Among the study population, we observed the highest aggregation levels in patients with ET. Since it has been confirmed that thrombin formation is higher in thrombocytosis than in healthy subjects, ${ }^{14}$ 
this supports the hypothesis that platelet-derived polyP enhances coagulation by amplifying thrombin generation at different steps, e.g., by activating procoagulant factors and cofactors (e.g., FVa or FXIa) or by neutralizing anticoagulants (e.g., TFPI). ${ }^{15,16}$ A growing body of data suggests that changes in lipid composition are necessary but not sufficient enough to account for platelet surface regulation of thrombin generation. ${ }^{17}$ Our results add to the existing data which show a decrease in platelet polyP content in patients with dense granule storage pool disease. ${ }^{18}$ In our study, platelets from thrombocytopenic patients had significantly elevated polyP content (Fig. 1).

There is still the question about the role of the higher polyP levels in thrombocytopenia. It could be regarded as a compensatory mechanism, where fewer platelets are more packed with polyP and can presumably exert to some extent its clot-forming action, like in patients with normal platelet counts. Interestingly, we observed a negative correlation between polyP concentration and platelet count, but only in the entire study population, which may somehow confirm this hypothesis (Fig. 2). It was previously demonstrated that when intracellular polyP gets released, it may induce responses through P2Y signaling; indeed, long-chain polyP induces thrombosis via FXII activation, but also leads to platelet activation and consumptive coagulopathy. ${ }^{5}$ This polyP action could in turn explain why some patients with low platelet counts do not present with bleeding; however, that issue remains to be elucidated. ${ }^{19}$ Importantly, in this study the subjects had a comparable mean platelet volume (MPV) between the groups, reflecting the average platelet size (Table 1). Since some forms of thrombocytopenia are characterized by abnormal platelet size, and patients with an elevated platelet volume may have less bleeding episodes than patients with the same platelet count of normal-sized platelets, we can exclude the influence of platelet size on both polyP concentration and aggregation. Recent advances in research on the mechanism of coagulation indicate that the role of platelet-derived polyP can be much more diverse, and this class of molecules appears to be a promising target in drug development.

\section{Study limitations}

This is a preliminary study exploring new field of platelet pathophysiology. The small study population, especially in the ET group, resulted from our inclusion criteria, which made recruitment difficult. We looked for subjects who had not been treated with any concomitant antiplatelet drugs. Moreover, the age of the patients with thrombocytopenia was significantly different from the other study groups, so it cannot be excluded that the observed results are age-dependent. We are aware that the data presented herein are underpowered for drawing firm conclusions, and should be considered only as an idea to generate and foster future research.

\section{Conclusions}

Platelet-derived polyP levels were elevated in patients with chronic primary thrombocytopenia in comparison with those with ET and healthy subjects. The polyP level did not correlate with platelet reactivity as measured with aggregation in any of the study groups. The increased levels of polyP observed in patients with low platelet counts may indicate the existence of a compensatory mechanism that prevents excessive bleeding in those patients. Our study provides evidence of an essential role of polyP in platelet function and the coagulation process.

\section{ORCID iDs}

Ewa Żurawska-Płaksej (1) https://orcid.org/0000-0001-8566-3943 Wiktor Kuliczkowski (1) https://orcid.org/0000-0001-6284-0820 Bożena Karolko (1) https://orcid.org/0000-0001-6253-1817 Magdalena Cielecka-Prynda (10) https://orcid.org/0000-0003-3779-6658 Jakub Dębski (1) https://orcid.org/0000-0002-2944-0929 Konrad Kaaz (1) https://orcid.org/0000-0001-5227-0027

Andrzej Mysiak (1) https://orcid.org/0000-0002-4728-2565

Tomasz Wróbel (1) https://orcid.org/0000-0002-6612-3535

Maria Podolak-Dawidziak (1) https://orcid.org/0000-0003-3987-3100

Lidia Usnarska-Zubkiewicz (1) https://orcid.org/0000-0002-5893-1989

\section{References}

1. Travers RJ, Smith SA, Morrissey JH. Polyphosphate, platelets, and coagulation. Int J Lab Hematol. 2015;37(1):31-35.

2. Morrissey JH, Smith SA. Polyphosphate as modulator of hemostasis, thrombosis, and inflammation. J Thromb Haemost. 2015;13(Suppl 1): S92-S97.

3. Mutch NJ. Polyphosphate as a haemostatic modulator. Biochem Soc Trans. 2016;44(1):18-24.

4. Morrissey JH. Contributions of platelet polyphosphate to hemostasis and thrombosis. In:SabaHI, Roberts HR, eds. Hemostasis andThrombosis. Oxford, UK: Wiley Blackwell UK; 2014:2360-2453.

5. Mailer RKW, Hänel L, Allende M, Renné T. Polyphosphate as a target for interference with inflammation and thrombosis. Front Med (Lausanne). 2019;6:1-10.

6. Montilla M, Hernandez-Ruiz L, Garcia-Cozar FJ, Alvarez-Laderas I, Rodríguez-Martorell J, Ruiz FA. Polyphosphate binds to human von Willebrand factor in vivo and modulates its interaction with glycoprotein Ib. J Thromb Haemost. 2012;10(11):2315-2323.

7. Nickel KF, Ronquist G, Langer F, et al. The polyphosphate-factor XII pathway drives coagulation in prostate cancer-associated thrombosis. Blood. 2015;126(11):1379-1389.

8. Verhoef JJF, Barendrecht AD, Nickel KF, et al. Polyphosphate nanoparticles on the platelet surface trigger contact system activation. Blood. 2017;129(12):1707-1717.

9. Schlagenhauf A, Pohl S, Haidl H, Leschnik B, Gallistl S, Muntean W. Non-enzymatic quantification of polyphosphate levels in platelet lysates and releasates. J Pharm Biomed Anal. 2016;131:1-5.

10. Smith SA, Morrissey JH. Polyphosphate enhances fibrin clot structure. Blood. 2008;112(7):2810-2816.

11. Mitchell JL, Lionikiene AS, Georgiev G, et al. Polyphosphate colocalizes with factor XII on platelet-bound fibrin and augments its plasminogen activator activity. Blood. 2016;128(24):2834-2845.

12. Whyte CS, Chernysh IN, Domingues MM, et al. Polyphosphate delays fibrin polymerisation and alters the mechanical properties of the fibrin network. Thromb Haemost. 2016;116(5):897-903.

13. Mutch NJ, Engel R, Uitte de Willige S, Philippou H, Ariëns RAS. Polyphosphate modifies the fibrin network and down-regulates fibrinolysis by attenuating binding of tPA and plasminogen to fibrin. Blood. 2010;115(19):3980-3988.

14. Duchemin J, Ugo V, lanotto J-C, Lecucq L, Mercier B, Abgrall J-F. Increased circulating procoagulant activity and thrombin generation in patients with myeloproliferative neoplasms. Thromb Res. 2010;126(3):238-242. 
15. Choi SH, Smith SA, Morrissey JH. Polyphosphate is a cofactor for the activation of factor XI by thrombin. Blood. 2011;118(26):6963-6970.

16. Wood JP, Petersen HH, Yu B, Wu X, Hilden I, Mast AE. TFPla interacts with $\mathrm{FVa}$ and $\mathrm{FXa}$ to inhibit prothrombinase during the initiation of coagulation. Blood Adv. 2017;1(27):2692-2702.

17. Monroe DM, Hoffman M, Robert HR. Platelets and thrombin generation. Atherosc Thromb Vasc Biol. 2002;22(9):1381-1389.
18. Hernández-Ruiz L, Sáez-Benito A, Pujol-Moix N, Rodríguez-Martorell J, Ruiz FA. Platelet inorganic polyphosphate decreases in patients with delta storage pool disease. J Thromb Haemost. 2009;7(2):361-363.

19. Melazzini F, Zaninetti C, Balduini CL. Bleeding is not the main clinical issue in many patients with inherited thrombocytopaenias. Haemophilia. 2017;23(5):673-681. 